\title{
Spontaneous regression of hepatocellular carcinoma
}

\author{
R C S Ayres, D A F Robertson, K C Dewbury, G H Millward-Sadler, C L Smith
}

\begin{abstract}
A 63 year old white woman presented with abdominal discomfort, anorexia, and weight loss. Investigations showed hepatocellular carcinoma with pulmonary metastases. The primary and secondary tumours resolved without specific treatment.
\end{abstract}

\section{Case report}

A 63 year old woman was admitted to hospital with a four month history of abdominal discomfort and bloating after eating. There was a one month history of anorexia and $3.2 \mathrm{~kg}$ weight loss with nausea but no vomiting. She had noted a mass in the right upper quadrant a week before admission, since when the abdominal discomfort had become progressively more severe. There was no relevant past history or family history. There was no previous history of jaundice or hepatitis, no excessive alcohol intake, no previous operations or blood transfusions, and she had been taking no drugs.

On examination she was thin, with evidence of recent weight loss. Palmar erythema was noted but no other stigmata of chronic liver disease. Irregular hepatomegaly was noted $8 \mathrm{~cm}$ below the costal margin. Her initial weight was $47 \cdot 5 \mathrm{~kg}$.

Investigations showed normal concentrations of urea, electrolytes, calcium, and phosphorus. The concentration of total protein was $81 \mathrm{~g} / \mathrm{l}$, albumin $41 \mathrm{~g} / \mathrm{l}$, and total bilirubin $10 \mu \mathrm{mol} / \mathrm{l}$; alkaline phosphatase activity was $549 \mathrm{IU} / \mathrm{l}$ (normal range 100-300 IU/l) (liver origin confirmed by isoenzymes), aspartate aminotransferase activity 101 IU/l (normal range < 40 IU/l), glucose concentration $4.2 \mathrm{mmol} / \mathrm{l}$, and $\gamma$ glutamyltransferase activity $207 \mathrm{IU} / \mathrm{l}$. The $\alpha$

Departments of Medicine 2, Radiology, and Pathology, Southampton General Hospital, Southampton, Hampshire SÓ9 4XY R C S Ayres

D A F Robertson

K C Dewbury

G H Millward-Sadler C L Smith

Correspondence to: Dr D A F Robertson, Department of Medicine, Royal United Hospital, Combe Park, Bath BAI 3NG.

Accepted for publication 21 August 1989

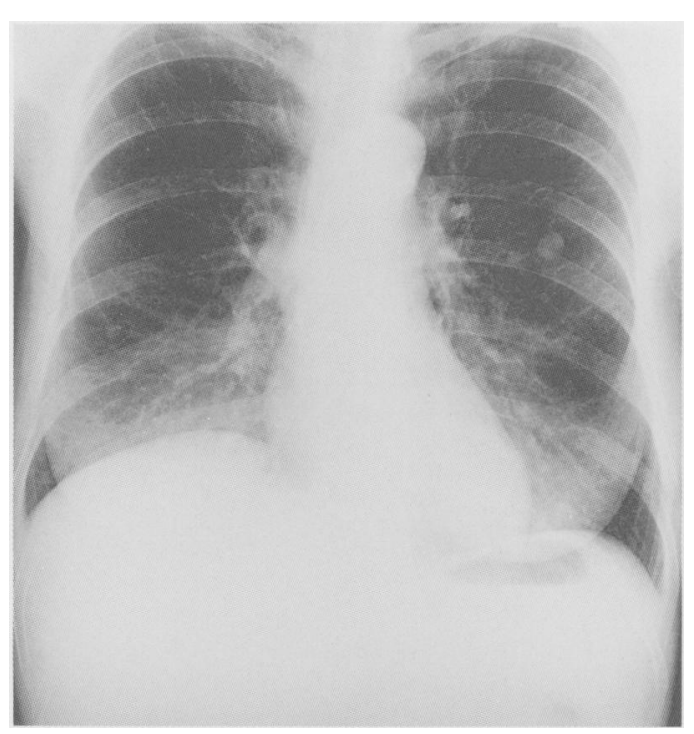

Figure 1: A posteroanterior chest radiograph. Note the slightly raised right hemidiaphragm. There are several rounded densities in both lung fields. The most easily seen is in the left mid-zone. The appearances are typical of metastases.

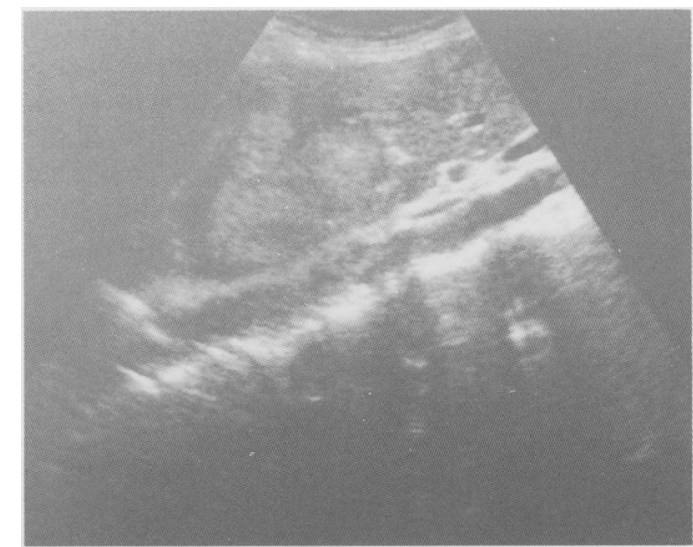

Figure 2: A longitudinal ultrasound scan through the left lobe of the liver over the aorta. A large lobular focal lesion is seen occupying the upper half of the left lobe of the liver.

fetoprotein concentration (immunoradiometric assay, Novo Labs) was appreciably raised at 7390 KAU/l (normal <10). Hepatitis B surface antigen and hepatitis $B$ antibodies including IgM anticore antibody and hepatitis A IgM were negative. The haemoglobin concentration was $11 \cdot 3 \mathrm{~g} / \mathrm{dl}$, mean cell volume $76 \cdot 8 \mathrm{fl}$, platelet count $379 \times 10^{9} / 1$, and white cell count $7 \cdot 5 \times 10^{\%} / 1$ with a normal differential count. A blood film showed normocytic and hypochromic red cells. The prothrombin time was 13 seconds and the serum ferritin concentration was normal at $143 \mathrm{IU} / 1$. The chest $x$ ray film showed a number of small round shadows at the bases and one large one in the left mid-zone; the appearance was that of metastatic disease (Fig 1). Ultrasound scanning showed multiple, large, highly reflective lesions suggestive of tumour in both left and right lobes of the liver (Figs 2 and 3). No other abnormality was seen. The patient underwent liver biopsy, which showed fragments of tumour composed of large polygonal cells arranged in sheets and

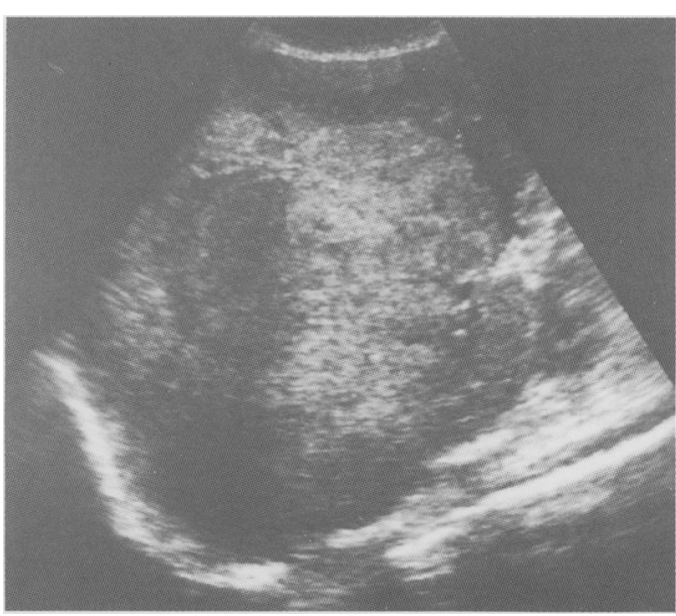

Figure 3: A longitudinal ultrasound scan through the right lobe of the liver. Almost the whole of the right lobe is replaced by a large lobular rounded focal lesion with a heterogeneous texture. The appearances are of a liver tumour. 


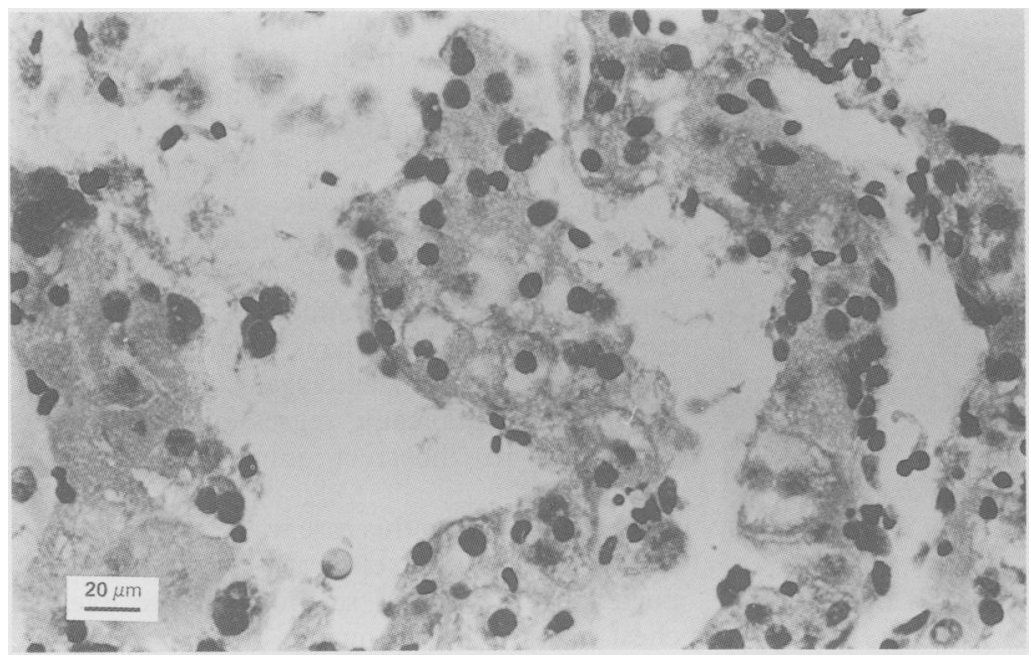

Figure 4: Tumour arranged in trabeculae two or more cell plates thick and separated by sinusoids. Haematoxylin and eosin.

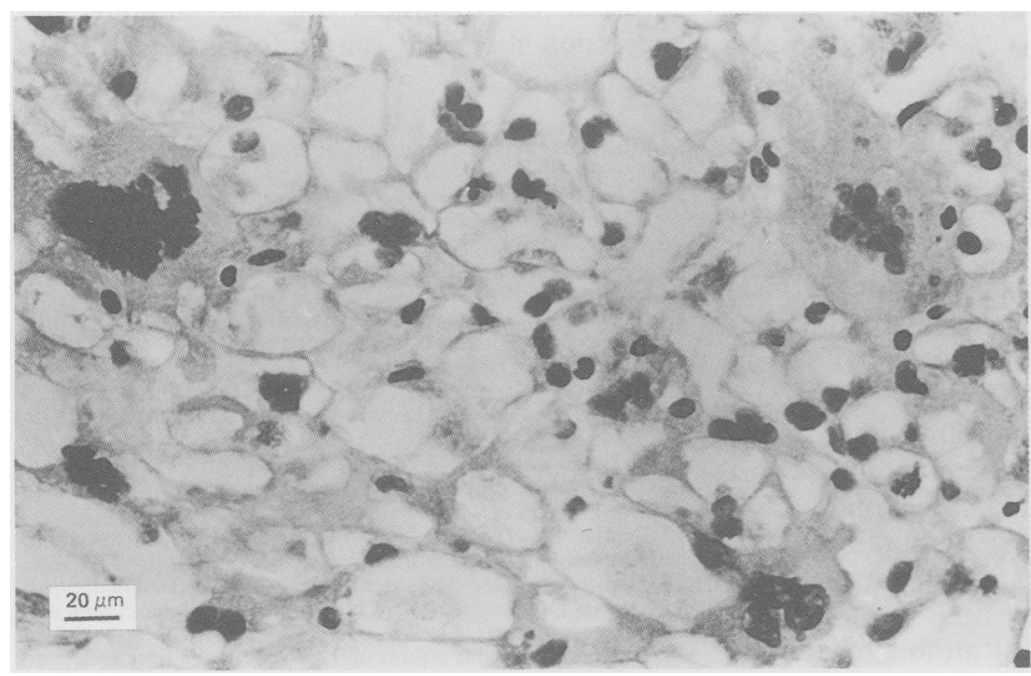

Figure 5: Solid clear cell area of tumour showing multinucleate tumour cells and an abnormal mitotic figure. Haematoxylin and eosin.

trabeculae with little intervening stroma but with a prominent sinusoidal structure. The tumour cells were pleomorphic, and several foci with bizarre giant nuclei and multinucleate cells were present. In between these foci the tumour cells were polygonal with either eosinophilic or clear cytoplasm and their large nuclei had prominent nucleoli. Many lymphocytes and mononuclear cells infiltrated the fragments of tumour. No non-neoplastic liver tissue was present. The appearances were those of a primary hepatocellular carcinoma (Figs 4 and 5).

No treatment was considered worth while, and the patient was discharged home with no drugs.

Five months later she was asymptomatic and had gained $3 \mathrm{~kg}$. A repeat chest $x$ ray examination showed that the metastases had cleared (Fig $6)$. The $\alpha$ fetoprotein concentration fell to $1 \mathrm{kU} / 1$. Repeat ultrasound scanning showed considerable shrinkage of the tumour (Figs 7 and 8) and a biopsy of the remaining abnormal area seen on ultrasound showed a cryptogenic macronodular cirrhosis with no evidence of carcinoma. One of the two cores of liver examined was almost entirely recent scar tissue. No evidence of piecemeal necrosis, hepatitis B infection, haemo-

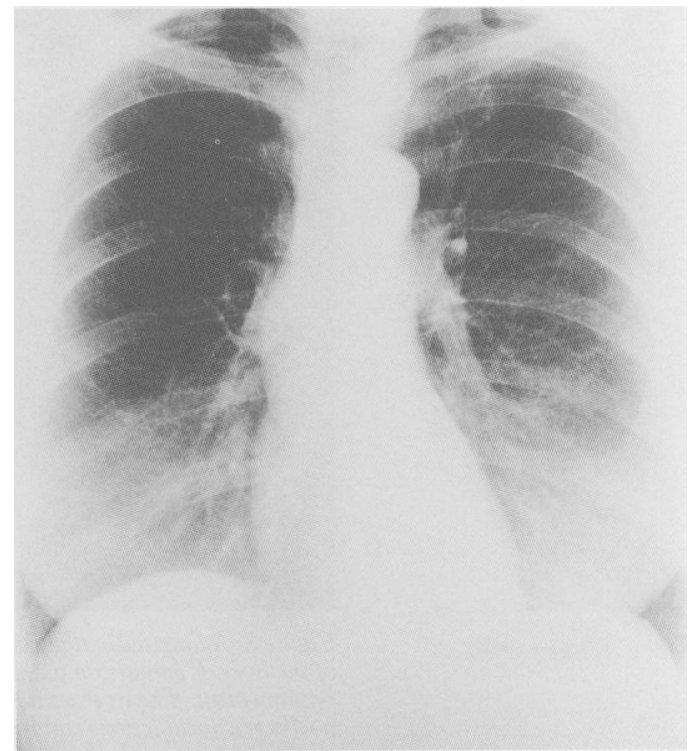

Figure 6: A follow up chest radiograph taken five months after that in Figure 1. The right hemidiaphragm is now in a normal position and the rounded metastases previously noted are no longer visible.

chromatosis, chronic biliary tract disease, $\alpha_{1}$ antitrypsin deficiency, or alcoholic liver disease could be found from the biopsy specimens. Twelve months after presentation she remained well with further weight gain and no recurrent symptoms. Liver function tests were normal.

\section{Discussion}

Primary hepatocellular carcinoma is the commonest malignancy world wide, although it is rare in Britain, and has a very poor prognosis with a mean survival of six months. ${ }^{1-3}$ Several risk factors are recognised. There is a male preponderance of three to one over females which is usually explained by the increased rate of ethanol abuse, chronic liver disease, and chronic hepatitis B infection in men. There is a well established association with hepatitis $\mathrm{B} .^{4-7}$ Hepatitis $\mathrm{B}$ virus DNA has been isolated from human hepatocellular carcinoma tissue from both necropsy and biopsy specimens, but only in patients with at least one marker of previous or

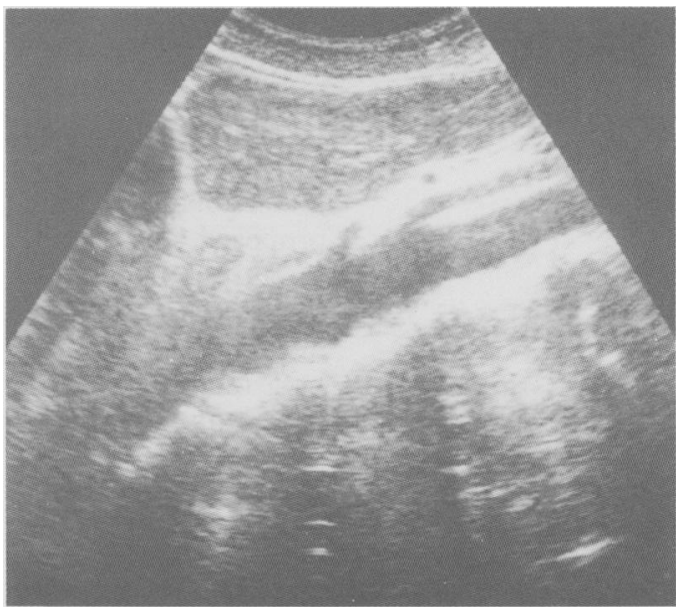

Figure 7: A longitudinal ultrasound scan through the left lobe of the liver. This is a comparative section to that in Figure 2 and there is no evidence here of any focal lesion in the left lobe of the liver. 


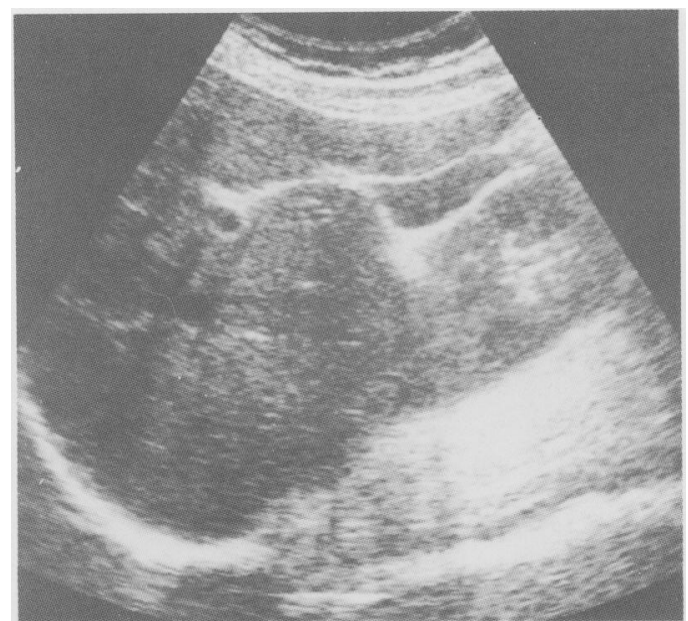

Figure 8: A longitudinal ultrasound scan through the right lobe of the liver. Comparison with Figure 3 shows a dramatic improvement. The liver texture is now essentially normal and no discrete focal lesions can be identified, although there is still slight distortion of the hepatic interlobar fissure in the position in which the previous focal lesion was noted.

current hepatitis $\mathrm{B}$ infection. ${ }^{8}$ An association with cirrhosis, not necessarily hepatitis B related, is recognised, with histological evidence of cirrhosis being found in between $60 \%$ and $90 \%$ of cases. ${ }^{910}$

Treatment is largely unsuccessful. Surgical options include resection or transplantation, but surgery is often precluded by the extent of spread at presentation. The results of chemotherapy are poor. The antimetabolite fluorouracil was one of the first cytotoxic agents to be investigated as a single agent treatment in a large number of patients, but the results of trials of both oral and intravenous use were poor ${ }^{11}$ and the drug is now rarely used. Remission has been induced with doxorubicin in some trials, ${ }^{12}{ }^{13}$ although in others this failed to show any benefit. ${ }^{14}$ is Survival is longer in young patients without cirrhosis and with low $\alpha$ fetoprotein levels and in those with well differentiated tumours. ${ }^{16} 17$

Spontaneous regression has been documented in malignant disease, although only two reports of spontaneous regression of primary hepatocellular carcinoma have been published..$^{19}$ In only one of these, in a Chinese patient who was positive for hepatitis B surface antigen, was there evidence of metastatic spread. ${ }^{18}$ The second case $^{19}$ occurred in a 65 year old alcoholic, the biopsy showing established cirrhosis as well as hepatocellular carcinoma.

The spontaneous regression of cancer is poorly understood, although various causes have been proposed.$^{20}$ Endocrine factors have been thought to be responsible for spontaneous regression of some cases of hypernephroma, malignant melanoma, and carcinoma of the ovary, testis, breast, and thyroid.

Immune mechanisms may occasionally be responsible for an effective host response to an established neoplasm and have therefore been implicated in some cases of spontaneous regression of cancer. Disruption of the blood supply to the tumour, either because of rapid tumour growth or after incomplete surgical removal, may result in tumour infarction and is implicated in the spontaneous regression of neuroblastoma. Cases of apparent spontaneous regression of cancer of the bladder have been attributed to removal of a carcinogenic agent. Other cases of apparent spontaneous regression have been attributed to incorrect initial diagnosis of malignancy.

The diagnosis in this case was established by a strongly suggestive clinical presentation supported by ultrasound scanning of the liver, a chest $x$ ray film showing discrete scattered opacities consistent with metastatic spread, and appreciably raised $\alpha$ fetoprotein concentrations and confirmed by liver biopsy. The patient received no treatment for the tumour and regression therefore can truly be described as spontaneous.

1 Chan CH. Primary carcinoma of the liver. Med Clin North Am 1975; 59: 989-94.

2 Desai HN. Clinical aspects of hepatocellular carcinoma in man. S Afr Med F 1976; 50: 1611-3.

3 Okuda K. Membranous obstruction of the inferior vena cava: etiology and relation to hepatocellular carcinoma. Gastroenterology 1982; 82: 376-8.

4 Vogel CL, Anthony PP, Mody N, Barker LF. Hepatitisassociated antigen in Ugandan patients with hepatocellular carcinoma. Lancet 1970; ii: $621-4$.

5 Szmuness W. Hepatocellular carcinoma and the hepatitis B virus. Evidence of a causal association. Prog Med Virol 1978; 24: 40-69.

6 Tabor E, Robert J, Gerety CL, et al. Hepatitis B virus infection and primary hepatocellular carcinoma. $\mathcal{F}$ Natl Cancer Inst 1977; 58: 1197-200

7 Beasley RP, Hwang LY, Lin CC, Chien CS. Hepatocellular carcinoma and hepatitis B virus. Lancet 1981; ii: 1129-32.

8 Shafritz DA, Kew MC. Identification of integrated hepatitis B virus DNA sequences in human hepatocellular carcinoma. virus DNA sequences in

9 Liver cancer study group of Japan. Primary liver cancer in Japan. Cancer 1984; 54: 1747-55.

10 Shikata T. Primary liver cancer and cirrhosis. In: Okuta $\mathrm{K}$, Peters RL, eds. Hepatocellular carcinoma. London: John Wiley, 1976: 53-72.

11 Dunk AA, Thomas HC. Hepatocellular carcinoma treatment. Aliment Pharmacol Ther 1988; 2: 187-201.

12 Johnson PJ, Williams R, Thomas $\mathrm{H}$, et al. Induction of remission of hepatocellular carcinoma with doxorubicin. Lancet 1978; i: 1006-9.

13 Olweny CLM, Toyal T, Katongole-Mbidde E, Mugerwa J, Kyalwazi SK, Cohen H. Treatment of hepatocellular carcinoma with Adriamycin (preliminary communication). Cancer 1975; 36: 1250-7.

14 Vogel CL, Bayley AC, Brooker RJ, Anthony PP, Ziegler JL. A phase II study of Adriamycin (NSC 123127) in patients with phase II study of Adriamycin (NSC 123127) in patients with hepatocellular carcinoma from

15 Scarrino E, Simonetti RG, Moli SL, Pagliaro L. Adriamycin treatment for hepatocellular carcinoma: experience with 109 patients. Cancer 1985; 56: 2751-5.

16 Matsumoto Y, Suzuki T, Asada I, et al. Clinical classification of hepatoma in Japan according to serial changes in alphafetoprotein levels. Cancer 1982; 49: 354-60.

17 Johnson PJ, Melia WM, Palmar MK, et al. Relationship between serum alpha-fetoprotein, cirrhosis and survival in hepatocellular carcinoma. Br $\mathcal{f}$ Cancer 1981; 44: 502-5.

18 Lam KC, Ho JCI, Yeung RTT. Spontaneous regression of hepatocellular carcinoma. Cancer 1982; 50: 332-6.

19 Gottfried EB, Steller R, Paronetto F, Lieber CS. Spontaneous regression of hepatocellular carcinoma. Gastroenterology 1982; 82: $770-4$

20 Everson TC, Cole WH. Spontaneous regression of cancer. Philadelphia: WB Saunders, 1966: 6-7. 